\title{
SEROLOGICAL AND SHEDDING PATTERNS AFTER COXIELLA BURNETII VACCINATION IN THE THIRD GESTATION TRIMESTER IN DAIRY COWS
}

\author{
Joan Tutusaus ${ }^{1}$, Fernando LóPez-Gatius ${ }^{1}$, Beatriz SerRano ${ }^{1}$, Eva MonleÓN ${ }^{2}$, \\ Juan José BADIOLA ${ }^{2}$ and Irina GARCIA-ISPIERTO ${ }^{*}$ \\ ${ }^{1}$ Agrotecnio Centre, University of Lleida, Av. Alcalde Rovira Roure 191, 25198 Lleida, \\ Spain; ${ }^{2}$ Centre for Research on Transmissible Spongiform Encephalopathies and \\ Emergent Diseases, University of Zaragoza, Zaragoza, Spain
}

(Received 17 April 2013; accepted 2 July 2013)

This study sought to assess the effects of an inactivated phase I vaccine against Coxiella burnetii at the start of the third trimester of gestation on serological profiles, bacterial shedding patterns and subsequent reproductive performance in dairy cows. Cows were randomly assigned to a control $(\mathrm{n}=78)$ or a vaccinated $(\mathrm{n}=78)$ group on days 171-177 of gestation. Samples of placenta and colostrums at parturition, vaginal fluid, faeces, milk (PCR identification) and blood (anti- $C$. burnetii antibody detection) were obtained on the day of treatment and on days 91-97 post partum, and also on parturition day and weekly on days $1-7,8-14$, $15-21,22-28$ and $29-35$ post partum in a subset of 70 animals. By Kaplan-Meier survival analysis, no significant effect of vaccination was detected on any of the reproductive variables studied. According to the odds ratio, $C$. burnetii shedding on days $171-177$ of gestation was highly correlated with seropositivity against $C$. burnetii $(\mathrm{OR}=9.1)$, while vaccination was not linked to reduced shedding of the bacterium. In shedders compared to others, the likelihood of pregnancy to first AI decreased and increased by factors of 0.26 and 16.1 on days 1-35 and 91-97 post partum, respectively. In conclusion, when administered at the start of the third trimester of pregnancy, the inactivated $C$. burnetii phase I vaccine failed to reduce bacterial shedding.

Key words: Coxiella burnetii, vaccination, shedding, infection, reproduction, pregnancy loss, bovine, infertility

Q fever is a re-emerging zoonotic disease caused by Coxiella burnetii, an obligate intracellular, Gram-negative bacterium. Coxiellosis in humans has been widely investigated and is known to produce mainly a flu-like syndrome and abortion. Domestic ruminants are the main reservoir and source of infection for humans (Arricau-Bouvery and Rodolakis, 2005). Although the effects of C. bur-

*Corresponding author; E-mail: irinag@prodan.udl.cat; Phone: 0034 (973) 706-454; Fax: 0034 (973) 702-874 
netii on small ruminants have been clearly established, reports of its impacts in cattle have been contradictory. Thus, some research efforts in dairy cattle have related the presence of specific antibodies against $C$. burnetii to reproductive disorders such as retained placenta or reduced fertility (López-Gatius et al., 2012), while other studies have observed no such relationship (Garcia-Ispierto et al., 2011). In addition, it has been reported that shedding cows are not always seropositive for $C$. burnetii and that not all seropositive animals shed the bacterium (Hansen et al., 2011). To further complicate matters, there are three possible shedding routes: via the milk, vaginal mucous or faeces (Guatteo et al., 2006); making it very difficult to detect this infection at the clinical level. Finally, vertical transmission has not been demonstrated by serology (Tutusaus et al., 2013).

Several vaccines against $C$. burnetii have been recently developed. So far, the phase I inactivated vaccine seems to be the most protective, inducing seroconversion and reducing bacterial shedding and abortion rates in seronegative and/or PCR-negative goats (de Cremoux et al., 2012). However, in dairy cattle, a Th2 immune response and reduced shedding has been observed only in nonpregnant animals that are seronegative and/or PCR-negative (Guatteo et al., 2008). Further, to the best of our knowledge, phase I vaccination has been only tested in the early post-insemination period or in the very early stages of embryonic development (Taurel et al., 2012). Given that, because of farm management policy, vaccination after artificial insemination (AI) is sometimes difficult, this study sought to determine the effect of an inactivated phase I vaccine against $C$. burnetii given at the starting of the third trimester of gestation (on days 171-177) on serological profiles, shedding patterns and the reproductive status of highproducing pregnant dairy cows. To this end, cows were monitored for antigen shedding and antibody production during the prepartum, periparturient and postpartum period (on a weekly basis), and also on days 91-97 post partum.

\section{Materials and methods}

The study was performed in two commercial Holstein-Friesian dairy herds in northeastern Spain, comprising 625 and 125 lactating animals, respectively, from October 2010 to October 2011. Cows were milked three times daily with a mean annual milk production of $11,343 \mathrm{~kg}$ and 9,846 kg for Herds 1 and 2, respectively. The cows calved all year round and were fed complete rations, in line with the National Research Council recommendations (2001). During the study period, mean calf mortality rate was $9 \%$ and mean conception rate was $33 \%$ for the two herds.

Vaccination programmes for the prevention of bovine viral diarrhoea (BVD) and infectious bovine rhinotracheitis (IBR) involved the use of modified live vaccines (Cattlemaster ${ }^{\mathbb{R}}$, Pfizer, New York, USA) for animals 6-8 months 
old. Pregnant animals were given killed vaccines (Triangle $4^{\circledR}$, Boehringer Ingelheim, Barcelona, Spain) during the eighth months of each gestation period. Parous cows that were not pregnant on day 150 post partum received a further killed vaccine. The presence of $C$. burnetii DNA in the bulk tank milk (BTM) was detected by polymerase chain reaction (PCR) in both herds with an excretion level higher than $10^{3}$ Coxiella/ml (Garcia-Ispierto et al., 2010, 2011; López-Gatius et al., 2012) and C. burnetii seroprevalence in Herds 1 and 2 was 28.2 and 18\%, respectively. According to the results of previous ELISA and PCR tests on BTM samples, both herds were known to be chronically infected with Coxiella burnetii.

Only animals free of clinical disease during the study period were included in the study. Exclusion criteria were mastitis, lameness and digestive disorders. These animals were excluded to minimise variations in the general health status of the animals so that serological changes could be attributed to factors other than the clinical condition of the cows during the study. Eventually, the data of a total of 156 cows were analysed.

\section{Insemination and pregnancy diagnosis}

Oestrus was detected using a pedometer system (AfiFarm System; SAE Afikim, Israel). Walking activity values were recorded at the milking parlour (three times daily) and analysed automatically using the herd management computer programme (López-Gatius et al., 2005). Cows that exhibited oestrus within a 12-day interval were also excluded and registered as cows with possible reproductive disorders. These animals were returned to a weekly gynaecological examination programme. Cows were finally inseminated after oestrus had been confirmed by examination of the genital tract and vaginal fluid. Pregnancy diagnosis was performed by ultrasound 28-34 days after insemination and confirmed on days 90-96 after insemination. Foetal loss was recorded when the days 90-96 diagnosis proved negative. Cows diagnosed as not pregnant and cows with no oestrous signs before days 71-77 in milk were included in a weekly reproductive programme and inseminated either following specific treatment (López-Gatius et al., 2008) or during natural oestrus. Data from cows suffering from any clinical disease before day 120 in milk (open cows) or before day 90 of gestation (pregnant cows) were withdrawn from the study. All gynaecological examinations and pregnancy diagnoses were performed by the same veterinarian.

\section{Experimental design}

At the beginning of the study, individual serological tests were performed in heifers (older than 12 months) and parous cows to determine the anti-C. burnetii antibody status of the herds. After these tests, 156 cows were randomly assigned to a control non-vaccinated $(n=78)$ or vaccinated $(n=78)$ group. Cows in the vaccinated group received two subcutaneous injections 3 weeks apart of inac- 
tivated phase I vaccine (Coxevac ${ }^{\circledR}$, CEVA Santé Animale, Libourne, France) on days 171-177 and days 192-198 of gestation. Each 4-mL vaccine dose contained purified corpuscular phase I C. burnetii antigens $(100 \mu \mathrm{g} / \mathrm{mL})$ inactivated with formaldehyde. Cows were sampled (blood, milk, vaginal fluid and faeces) twice during the study period: on days 171-177 of pregnancy and on days 91-97 post partum. The final study population comprised 117 parous animals and 39 heifers.

A subset of 70 of the 156 cows underwent more intensive monitoring. These cows were sampled 8 times during the study period: on days 171-177 of gestation, on the day of parturition and on days 1-7, 8-14, 15-21, 22-28, 29-35 and 91-97 post partum. Besides blood, milk, vaginal fluid and faeces, on the day of parturition placenta and colostrum samples were also collected.

\section{Sampling procedures}

Blood. Blood samples were collected from the coccygeal vein into heparinised vacuum tubes (BD Vacutainer ${ }^{\mathrm{TM}}$, Becton, Dickinson and Company, Plymouth, UK). Tubes were centrifuged $(10 \mathrm{~min}, 1600 \times \mathrm{g})$ within $30 \mathrm{~min}$ of collection and the plasma stored at $-20{ }^{\circ} \mathrm{C}$ until analysis.

Milk and colostrum. These samples were collected in a plastic sterile container for PCR. To minimise the risk of contamination during the collection process, teats were washed in clean water and then each teat end was scrubbed using an antiseptic wipe. Finally, milk and colostrum were collected from the four teats after elimination of the initial stream. Samples were frozen at $-20{ }^{\circ} \mathrm{C}$ prior to analysis.

Vaginal fluid. To obtain a vaginal fluid sample, the vulva was disinfected with iodine solution, and a vaginal swab obtained and stored at $-20^{\circ} \mathrm{C}$.

Faeces. Faecal samples were collected into sterile containers using a rectal examination glove and stored at $-20^{\circ} \mathrm{C}$.

Placenta. Specimens of the placenta were obtained immediately after parturition. After washing the perineum with iodine solution, three cotyledons were excised using rectal palpation gloves. After their collection, the specimens were stored at $-20^{\circ} \mathrm{C}$ until PCR analysis.

\section{Clinical examination}

During four scheduled herd visits (V1-V4), examinations were performed on days 15-21 (V1), 22-28 (V2), 29-35 (V3) and 51-57 (V4) post partum by the same veterinarian. The clinical examination included ultrasonography (US) of the genital tract and ovaries and examination of vaginal fluid (appearance and odour). The entire reproductive tract was examined by ultrasound using a portable B-mode ultrasound scanner (Easi-scan ${ }^{\circledR}$ with a $7.5 \mathrm{MHz}$ transducer). In Visit 1 , cows were classed as suffering from endometritis according to the criteria described by López-Helguera et al. (2012): the presence of echogenic intrauterine fluid (IUF), a cervical diameter of $\geq 4 \mathrm{~cm}$ or an endometrial thickness $\geq 0.75 \mathrm{~cm}$. 


\section{Laboratory tests}

Antibodies to Coxiella burnetii. Antibodies to C. burnetii were detected in plasma samples by indirect enzyme-linked immunosorbent assay (ELISA) using the CoxLS kit (LSIVET RUMINANT Milk/Serum Q FEVER ${ }^{\circledR}$, Laboratoire Service International, Lissieu, France). This validated test (García-Pérez et al., 2009) was performed according to the manufacturer's instructions. The sensitivity and specificity of ELISA are $85 \%$ and $95 \%$, respectively (Courcoul et al., 2010). The antigen for the ELISA CoxLS kit was isolated from domestic ruminants by INRA in Nouzilly (France). A cocktail of both antigen phases (I and II) was used in this assay to detect total anti-C. burnetii immunoglobulin $\mathrm{G}$ antibodies (IgG) (Guatteo et al., 2008). Results are expressed as optical densities (OD). For each sample, the sample-to-positive $(\mathrm{S} / \mathrm{P})$ ratio was calculated as follows: sample OD minus negative control OD/positive control OD minus negative control OD, and expressed as an antibody titre (titre $=\mathrm{S} / \mathrm{P} \times 100$ ).

Polymerase chain reaction. Coxiella burnetii was detected by PCR in the samples using a commercial kit targeting the repetitive transposon-like region of C. burnetii (LSI Taqvet Coxiella burnetii ${ }^{\mathbb{B}}$; Laboratoire Service International, Lissieu, France) according to the manufacturer's instructions. The positive control used was a solution containing $10^{5}$ C. burnetii/mL (UR INRA IASP, Nouzilly, France). The negative control sample used was DNase RNase-free water. DNA was extracted from the different samples using the QIAmp DNA minikit ${ }^{\circledR}$ (Qiagen S.A., Courtaboeuf Cedex, France) according to the manufacturer's instructions.

\section{Data collection and statistical analysis}

The following data were recorded for each animal: herd, treatment group (vaccination vs. control), parity (primiparous vs. multiparous), stillbirth, reproductive disorders following calving (retained placenta and primary metritis), date and season of parturition (cool season: October-April vs. warm season: AprilSeptember), endometritis (0: absence, 1: presence), twinning, milk production at 50 days post partum (low milk production: less than $40 \mathrm{~kg} /$ day; high milk production: 40 or more $\mathrm{kg} /$ day), and reproductive variables for the subsequent lactation such as cow cyclicity (presence or absence of a corpus luteum within the first 35 days post partum), fertility at first AI, pregnancy rate on day 150 post partum, repeat breeding syndrome (four or more AIs), date of the AI resulting in pregnancy, pregnancy loss (pregnancy loss before 90 days post partum), anti- $C$. burnetii antibody status on days 171-177 of pregnancy and C. burnetii shedding via any of the four possible routes (milk, faeces, vaginal fluid, and the placenta at parturition) on days 171-177 of pregnancy, on the day of parturition, and on days $1-7,8-14,15-21,22-28,29-35$ and $91-97$ post partum. 
All statistical procedures were performed using the SPSS software package version 18.0 (SPSS Inc., Chicago, IL, USA). Significance was set at $\mathrm{P}<0.05$.

The variables mean time of return to luteal activity and AI resulting in pregnancy for the treatment group were compared with the remaining variables by Kaplan-Meier survival analysis. Cows not returning to cyclicity before day 35 post partum or culled before 150 days post partum were censored in each analysis.

Logistic regression was performed on data from each cow using C. burnetii shedding (in any type of sample at parturition, on days 1-35 post partum and on days 91-97 post partum), C. burnetii seropositivity, pregnancy loss, repeat breeding syndrome, fertility at first AI and retained placenta as the dependent variable and the above-mentioned remaining variables as independent factors. Plausible interactions between factors were also included in the analyses.

\section{Results}

The study sample comprised 156 pregnant cows, 78 vaccinated, with a mean lactation number of 2.8, ranging from 1 to 6 . At the study outset, 66 cows were seropositive for $C$. burnetii (42.3\%) and 90 were seronegative. Bacterial shedding was observed in $38(24.4 \%)$ and $12(7.7 \%)$ of the dams in the prepartum or postpartum period (in at least one postpartum sample), respectively. All cows included in the study delivered at term. After parturition, 26 cows had retained placenta (17\%). Eight of the 156 animals included in the study were not inseminated due to culling for economic reasons. Forty-four of the inseminated cows showed repeat breeding syndrome $(29.7 \%)$.

\section{Table 1}

Coxiella burnetii serological profiles and shedding patterns before and after treatment

\begin{tabular}{|c|c|c|c|c|c|}
\hline \multirow[b]{2}{*}{ Treatment } & \multirow[b]{2}{*}{ Sampling time } & \multicolumn{2}{|c|}{ Seropositive } & \multicolumn{2}{|c|}{ Seronegative } \\
\hline & & $\begin{array}{c}\mathrm{PCR}+ \\
\mathrm{n}(\%)\end{array}$ & $\begin{array}{l}\mathrm{PCR}- \\
\mathrm{n}(\%)\end{array}$ & $\begin{array}{c}\mathrm{PCR}+ \\
\mathrm{n}(\%)\end{array}$ & $\begin{array}{c}\mathrm{PCR}- \\
\mathrm{n}(\%)\end{array}$ \\
\hline Vaccinated $(\mathrm{n}=78)$ & $\begin{array}{l}171-177^{\mathrm{a}} \\
91-97 \mathrm{pp}^{\mathrm{b}}\end{array}$ & $\begin{array}{c}13(16.7) \\
4(5)\end{array}$ & $\begin{array}{l}23(29.5) \\
58(74)\end{array}$ & $\begin{array}{l}8(10.3) \\
1(1.3)\end{array}$ & $\begin{array}{l}34(43.6) \\
15(19)\end{array}$ \\
\hline Control $(\mathrm{n}=78)$ & $\begin{array}{l}171-177^{\mathrm{a}} \\
91-97 \mathrm{pp}^{\mathrm{b}}\end{array}$ & $\begin{array}{r}11(14) \\
5(6.4)\end{array}$ & $\begin{array}{l}19(24.4) \\
28(36)\end{array}$ & $\begin{array}{l}6(7.7) \\
2(2.6)\end{array}$ & $\begin{array}{l}42(53.8) \\
43(55)\end{array}$ \\
\hline
\end{tabular}

adays $171-177$ of gestation; ${ }^{\text {b days }} 91-97$ post partum

Serological profiles and shedding patterns for all cows on days 171-177 of gestation and days 91-97 post partum are presented in Table 1. Control cows seronegative for $C$. burnetii did not undergo seroconversion during the study period, whereas all control seropositive cows remained seropositive. Twenty-six 
$(61.9 \%)$ of the vaccinated animals seroconverted after vaccination. The routes of shedding during the study period for all cows are shown in Table 2. Figures 1 and 2 show the changes produced in serological profiles and shedding patterns throughout the study period, respectively, in the subgroup of 70 cows.

\section{Table 2}

Samples giving a positive PCR result for Coxiella burnetii according to the time of collection and the shedding route. Percentages refer to the total number of a given sample type for a given period

\begin{tabular}{lccc}
\hline Type of sample & $\begin{array}{c}\text { Days 171-177 of pregnancy } \\
\mathrm{n}(\%)\end{array}$ & $\begin{array}{c}\text { Days 91-97 post partum } \\
\mathrm{n}(\%)\end{array}$ & $\begin{array}{c}\text { Both periods } \\
\mathrm{n}(\%)\end{array}$ \\
\hline Vaginal fluid & $5(3.2)$ & $2(1.3)$ & $0(0)$ \\
Faeces & $16(10.3)$ & $5(3.2)$ & $1(0.6)$ \\
Milk & $14(9)$ & $1(0.6)$ & $2(1.3)$ \\
\hline
\end{tabular}

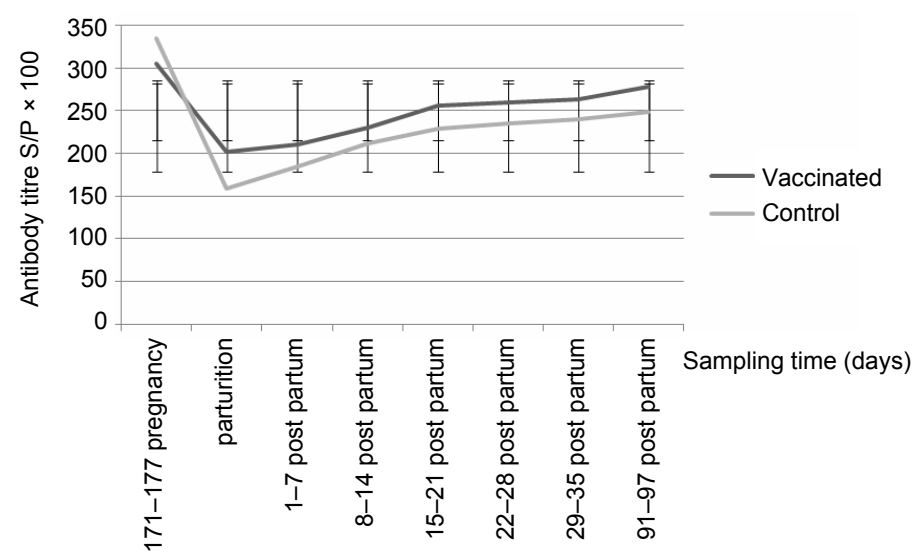

Fig. 1. Antibodies to Coxiella burnetii recorded throughout the study in vaccinated and control seropositive cows

No significant differences were detected by Kaplan-Meier survival analysis in the mean time to pregnancy diagnosis/conception until day 150 post partum and to return to luteal activity until day 35 post partum for any of the variables examined.

According to the odds ratio, the likelihood of $C$. burnetii shedding after 171-177 days of pregnancy was 9.1 times higher in C. burnetii seropositive cows than seronegative cows $(\mathrm{P}=0.004)$, while vaccination had no effect on shedding. In shedding cows compared to non-shedding animals, the likelihood of pregnancy to first AI was reduced by a factor of $0.26(\mathrm{P}=0.03)$ and increased by a factor of $16.1(\mathrm{P}=0.02)$ on days $1-35$ and days $91-97$ post partum, respectively. 


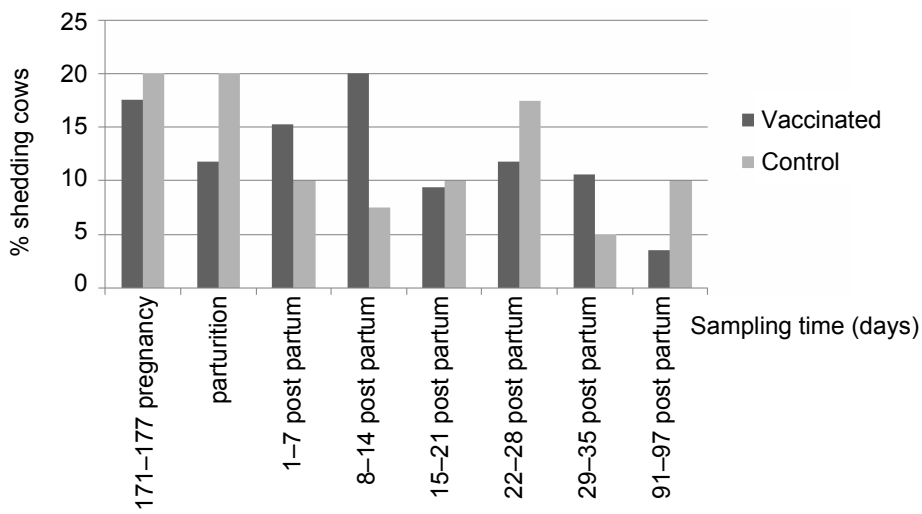

Fig. 2. Percentages of cows in the vaccinated and control groups shedding Coxiella burnetii by at least one route (milk, faeces, vaginal fluid, or placenta at parturition) throughout the study

\section{Discussion}

As far as we are aware, the pertinent literature lacks reports on C. burnetii vaccination trials conducted during advanced pregnancy in high-producing dairy cows. Despite several descriptions of reduced shedding loads produced in response to vaccination against $C$. burnetii (de Cremoux et al., 2012), the present findings suggest there is no link between vaccination and shedding load in pregnant cows. These results are consistent with those of other studies performed in animals vaccinated after AI (Guatteo et al., 2008). Probably, the inefficiency of the vaccine in pregnant animals is due to hormonal changes produced in pregnancy. During gestation, there is a shift towards the Th2 immune response at the expense of Th1, the cellular immune response (Druckmann and Druckmann, 2005) which could interfere with the response to vaccination. Thus, vaccinating all animals on farms with herds chronically infected with $C$. burnetii may not be an effective measure to reduce shedding.

Cows observed here to shed the bacterium on days 91-97 post partum showed improved subsequent fertility at first AI over non-shedders. This observation is in agreement with our suggestion based on prior findings (Garcia-Ispierto et al., 2012) that non-infected animals are not protected against the bacterium and consequently may be more susceptible to infection. However, cows shedding during the first five weeks post partum showed a lower fertility at first AI than non-shedders over this period. Recently, vaccination in goats was reported to increase milk shedding from hours to 9 days or more after vaccination (Hermans et al., 2011). Thus, it could be that postvaccination shedding masks shedding patterns within the first weeks of vaccination. Future studies should try to determine whether cows shed live bacteria after vaccination or, in other words, whether the difference between control and vaccinated animals is simply that vaccinated cows shed dead bacteria. 
A seroconversion rate of $61.9 \%$ was recorded on days $91-97$ post partum in seronegative vaccinated dams. Despite no seroconversion rates are available in the literature for inactivated $C$. burnetii phase I vaccination of dairy cattle, similar rates have been reported for dairy sheep in northern Spain (Astobiza et al., 2011).

In the subgroup of 70 animals, plasma $C$. burnetii antibody levels were observed to fall at parturition. This drop could be the result of antibody migration from peripheral blood to the mammary glands to produce colostrum (Herr et al., 2011). However, vaccinated animals showed a less pronounced decline in antibodies which remained elevated until three months post partum relative to the levels recorded in control cows. This could be attributable to the Th2 immune response induced by the vaccine.

According to other authors, $C$. burnetii seropositivity is a risk factor for bacterial shedding (Courcoul et al., 2010). Moreover, consistent with our findings, seroconversion is not observed in non-vaccinated animals (Böttcher et al., 2011; Nogareda et al., 2012) reflecting the high stability of $C$. burnetii antibodies. Finally, all the cows included in this study delivered at term, with no vaccine-associated abortions observed, indicating the safety of this vaccine.

In conclusion, the vaccination of pregnant dairy cows with an inactivated C. burnetii phase I vaccine at the start of the third trimester of pregnancy did not reduce shedding of the bacterium. Irrespective of vaccination, shedding levels during the postpartum period were related to fertility in response to first AI.

\section{Acknowledgements}

The authors thank the owners and staff of the farms for their co-operation and Ana Burton for assistance with the English translation. Joan Tutusaus was supported by a grant from the University of Lleida.

\section{References}

Arricau-Bouvery, N. and Rodolakis, A. (2005): Is Q fever an emerging or re-emerging zoonosis? Vet. Res. 36, 327-349.

Astobiza, I., Barandika, J. F., Ruiz-Fons, F., Hurtado, A., Povedano, I., Juste, R. A. and García-Pérez, A. L. (2011): Coxiella burnetii shedding and environmental contamination at lambing in two highly naturally-infected dairy sheep flocks after vaccination. Res. Vet. Sci. 91, 58-63.

Böttcher, J., Vossen, A., Janowetz, B., Alex, M., Gangl, A., Randt, A. and Meier, N. (2011): Insights into the dynamics of endemic Coxiella burnetii infection in cattle by application of phase-specific ELISAs in an infected dairy herd. Vet. Microbiol. 151, 291-300.

Courcoul, A., Vergu, E., Denis, J. B. and Beaudeau, F. (2010): Spread of Q fever within dairy cattle herds: key parameters inferred using a Bayesian approach. Proc. Biol. Sci. 22, 2857-2865.

de Cremoux, R., Rousset, E., Touratier, A., Audusseau, G., Nicollet, P., Ribaud, D., David, V. and Le Pape, M. (2012): Coxiella burnetii vaginal shedding and antibody responses in dairy goat herds in a context of clinical Q fever outbreaks. FEMS Immunol. Med. Microbiol. 64, $120-122$. 
Druckmann, R. and Druckmann, M. A. (2005): Progesterone and the immunology of pregnancy. J. Steroid Biochem. Mol. Biol. 97, 389-396.

García-Ispierto, I., Nogareda, C., Yániz, J. L., Almería, S., Martínez-Bello, D., de Sousa, N. M., Beckers, J. F. and López-Gatius, F. (2010): Neospora caninum and Coxiella burnetii seropositivity are related to endocrine pattern changes during gestation in lactating dairy cows. Theriogenology 15, 212-220.

Garcia-Ispierto, I., Almería, S. and López-Gatius, F. (2011): Coxiella burnetii is highly stable throughout gestation in lactating high-producing dairy cows. Reprod. Domest. Anim. 46, $1067-1072$.

Garcia-Ispierto, I., López-Helguera, I., Tutusaus, J., Serrano, B., Monleón, E., Badiola, J. J. and LópezGatius, F. (2012): Coxiella burnetii shedding during the peripartum period and subsequent fertility in dairy cattle. Reprod. Dom. Anim. DOI: 10.1111/rda.12095 ISSN 0936-6768.

García-Pérez, A. L., Astobiza, I., Barandika, J. F., Atxaerandio, R., Hurtado, A. and Juste, R. A. (2009): Short communication: investigation of Coxiella burnetii occurrence in dairy sheep flocks by bulk-tank milk analysis and antibody level determination. J. Dairy Sci. 92, 1581-1584.

Guatteo, R., Beaudeau, F., Berri, M., Rodolakis, A., Joly, A. and Seegers, H. (2006): Shedding routes of Coxiella burnetii in dairy cows: implications for detection and control. Vet. Res. 37, 827-833.

Guatteo, R., Seegers, H., Joly, A. and Beaudeau, F. (2008): Prevention of Coxiella burnetii shedding in infected dairy herds using a phase I C. burnetii inactivated vaccine. Vaccine 26, 4320-4328.

Hansen, M. S., Rodolakis, A., Cochonneau, D., Agger, J. F., Christoffersen, A. B., Jensen, T. K. and Agerholm, J. S. (2011): Coxiella burnetii associated placental lesions and infection level in parturient cows. Vet. J. 190, 135-139.

Hermans, M. H. A., Huijsmans, C. J. J., Schellekens, J. J. A., Savelkoul, P. H. M. and Wever, P. C. (2011): Coxiella burnetii DNA in goat milk after vaccination with Coxevac ${ }^{\circledR}$. Vaccine 29, 2653-2656.

Herr, M., Bostedt, H. and Failing, K. (2011): IgG and IgM levels in dairy cows during the periparturient period. Theriogenology 75, 377-385.

López-Gatius, F., Almeria, S. and Garcia-Ispierto, I. (2012): Serological screening for Coxiella burnetii infection and related reproductive performance in high producing dairy cows. Res. Vet. Sci. 93, 67-73.

López-Gatius, F., Mirzaei, A., Santolaria, P., Bech-Sábat, G., Nogareda, C., Garcia-Ispierto, I., Hanzen, C. H. and Yániz, J. L. (2008): Factors affecting the response to the specific treatment of several forms of clinical anestrus in high producing dairy cows. Theriogenology 69, 1095-1103.

López-Gatius, F., Santolaria, P., Mundet, I. and Yániz, J. L. (2005): Walking activity at estrus and subsequent fertility in dairy cows. Theriogenology 63, 1419-1429.

López-Helguera, I., López-Gatius, F. and Garcia-Ispierto, I. (2012): The influence of genital tract status in postpartum period on the subsequent reproductive performance in high producing dairy cows. Theriogenology 77, 1334-1342.

National Research Council (2001): Nutrient Requirements of Dairy Cattle. Seventh revised edition. National Academy Press, Washington D. C.

Nogareda, C., Almería, S., Serrano, B., Garcia-Ispierto, I. and López-Gatius, F. (2012): Dynamics of Coxiella burnetii antibodies and seroconversion in a dairy cow herd with endemic infection and excreting high numbers of the bacterium in the bulk tank milk. Res. Vet. Sci. 93, $1211-1212$.

Taurel, A. F., Guatteo, R., Joly, A. and Beaudeau, F. (2012): Effectiveness of vaccination and antibiotics to control Coxiella burnetii shedding around calving in dairy cows. Vet. Microbiol. 159, 432-437.

Tutusaus, J., López-Gatius, F., Almería, S., Serrano, B., Monleón, E., Badiola, J. J. and Garcia-Ispierto, I. (2013): No detectable precolostral antibody response in calves born from cows with cotyledons positive for Coxiella burnetii by quantitative PCR. Acta Vet. Hung. 61, 432-441. 